\section{Editorial: On IRIE Vol. 7}

The 7th volume of IRIE (01/2007) is dedicated entirely to the publication of the proceedings of the first African Information Ethics Conference (http://www.africainfoethics.org/) that was held in February, 5-7, 2007 in Pretoria, South Africa. It was co-organized by the University of Pretoria, the University of Wisconsin-Milwaukee and the ICIE International Center for Information Ethics and fully sponsored by the South African Government.

Under the heading 'the joy of sharing knowledge' and the patronage of UNESCO it brought together some 80 policy makers and academic minds from Africa and around the world to discuss the impact of the use of modern Information and Communication Technologies (ICTs) on the African continent and formulate a specifically African perspective on the challenges involved - locally and globally.

In addressing the ethical challenges of the information society on the African continent the conference was inspired by the Geneva Declaration adopted by the Geneva World Summit on Information Society (WSIS) of 2003. It was explicitly conceived as part of the implementation of Action Line C10 of the Geneva Plan of Action.

Besides the intercultural dialogue between scholars from Africa and around the globe that can be referred to in the proceedings published in this issue the conference produced some tangible results:

- The Tshwane Declaration as adopted by the participants of the conference as a genuine African contribution to the Code of Ethics for the Information Society

- The ANIE - African Network for Information Ethics to give African scholars a platform to exchange and realize their ideas in the field

- The claim to implement Advisory Boards to African Governments to give advice to policy makers on the continent regarding the ethical implications of ICTs.

- The African Reader on Information Ethics consisting of a selection of useful articles of this issue translated into main African languages.
The contributions to the conference published in this issue can be divided into 3 categories:

1. African Information Ethics in the context of the global Information Society (articles 1 15)

2. Information Ethics issues in Africa (articles 16 - 31)

3. Action Items for the road ahead (articles 32 - 39)

We hope you will appreciate this very special issue of IRIE as a valuable input for your academic and professional work.

Yours sincerely,

the Editors 